\title{
Synthesis of Amides from Acid Chlorides and Amines in the Bio-based Solvent Cyrene $^{\mathrm{TM}}$
}

\author{
Thomas W. Bousfield ${ }^{a}$, Katharine P. R. Pearce ${ }^{a}$, Simbarashe B. Nyamini ${ }^{a}$, Athanasios Angelis- \\ Dimakis $^{a}$ and Jason E. Camp*,a,b \\ ${ }^{a}$ Department of Chemical Sciences, University of Huddersfield, Queensgate, Huddersfield, U.K. \\ ${ }^{b}$ Department of Chemistry, University of Bath, Bath, U.K.
}

\author{
j.e.camp@hud.ac.uk
}

\begin{abstract}
Cyrene $^{\mathrm{TM}}$ as a bio-alternative dipolar aprotic solvent: a waste minimizing and molar efficient protocol for the synthesis of amides from acid chlorides and primary amines in the bio-available solvent Cyrene $^{\mathrm{TM}}$ is disclosed. This protocol removed the use of toxic solvents, such as dimethylformamide and dichloromethane. A simple aqueous work-up procedure for the removal of the high boiling solvent Cyrene $^{\mathrm{TM}}$ resulted in up to a 55-fold increase in molar efficiency (Mol E.\%) versus standard operating procedures. In order to rapidly compare the molar efficiency of this process against other methodologies an Excel based Mol. E\% calculator was developed that automates many of the calculations. An investigation into the hydration of Cyrene ${ }^{\mathrm{TM}}$ found that it readily hydrates to form a geminal diol in the presence of water and that this process is exothermic.
\end{abstract}

\section{KEYWORDS}

Cyrene $^{\mathrm{TM}}$, Green Solvents, Amide, Molar Efficiency, Metrics Calculator

\section{INTRODUCTION}

Amides are an important class of compound that have been exploited in a number of fields, such as the pharmaceutical, agrochemical and material sciences. Amides have had a profound impact on the pharmaceutical industry as highlighted by the large number of drugs that contain an amide moiety as well as the significant percentage of reactions performed by medicinal chemists to form amide linkages. ${ }^{1}$ Most of the top-15 best selling drugs in 2017 contained an amide, ${ }^{2}$ with amide drugs traditionally being some of the highest grossing of all time (Figure 1). ${ }^{3}$ Furthermore, amides themselves are increasingly exploited as catalysts, ligands, reagents, solvents and substrates for a multitude of synthetic transformations. ${ }^{4}$

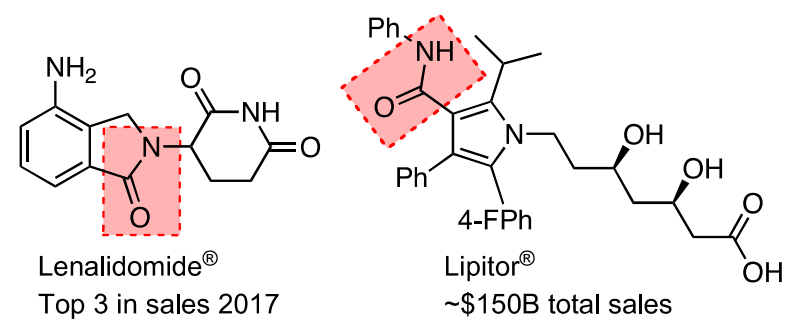

Figure 1 Important amide pharmaceuticals

Due to their importance, novel methods for the synthesis of amides are constantly being developed. ${ }^{5}$ One of the most efficient and highly utilized methods for the synthesis of amides is the reaction of acid chlorides and amines. For example a series of acid chlorides were reacted with anilines to give amides, which were screened as positive allosteric modulators of metabotropic glutamate receptor 4 with CNS 
exposure in rats (Scheme 1, eq. 1). ${ }^{6}$ In this typical example, a variety of amides were synthesized in good yields using the solvent dimethylformamide (DMF), but extensive work-up and purification protocols were required, including aqueous washing and column chromatography. Amides can be synthesized in a variety of different reaction media, though the majority of reactions have been performed in DMF, $\mathrm{N}$-methyl-2-pyrrolidone (NMP), dichloromethane $\left(\mathrm{CH}_{2} \mathrm{Cl}_{2}\right)$ or tetrahydrofuran (THF). ${ }^{7}$ There has been increased regulatory constraints placed on toxic, petroleum-based solvents that are the mainstay of industrial synthesis. The development of safer solvents is one of the core tenets of the twelve principles of Green Chemistry. ${ }^{8}$ One reason behind the inclusion of solvents in this key list is that between $75-80 \%$ of waste associated with the synthesis of pharmaceuticals comes from solvents. ${ }^{9}$ In order to combat the cost of solvents, in terms of time, expense and to the environment, a variety of solvent selection guides were put forward. ${ }^{10}$ One key class of solvent that currently does not have a direct replacement are dipolar aprotic, such as $N, N$-dimethylformamide (DMF) and $N$-methyl-2pyrrolidone (NMP). ${ }^{11}$ Both of these compounds were recently added to the REACH restricted substances list, which severely limits their ability to be used as industrial solvents. ${ }^{12}$ Thus, academic researcher and industry have put significant efforts into developing sustainable chemical processes that do not rely on high risk solvents. ${ }^{13,14}$

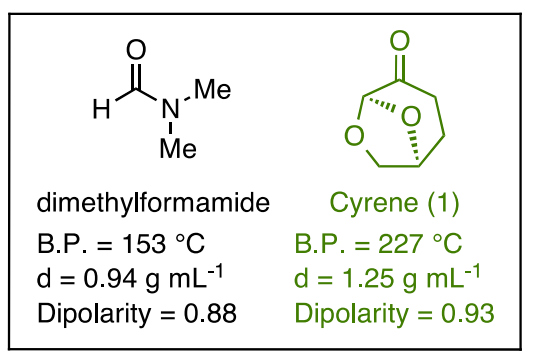

Figure 2 Comparison of the physical properties of DMF and Cyrene ${ }^{\mathrm{TM}}(\mathbf{1})$

A possible alternative dipolar aprotic solvent ${ }^{15}$ is the bio-available compound Cyrene ${ }^{\mathrm{TM}}$ (1), dihydrolevoglucosenone, which can be synthesized in two-step processes from waste cellulose. ${ }^{16}$ Cyrene $^{\mathrm{TM}}$ (1) has similar properties to other dipolar aprotic solvents, such as DMF, and it has been put forward as a bio-based alternative for this class of solvent (Figure 2). Since being proposed by Clark and co-workers in 2014 as a potential bioavailable solvent, Cyrene ${ }^{\mathrm{TM}}$ (1) has been utilized in a number of applications. ${ }^{17}$ For example, Cyrene ${ }^{\mathrm{TM}}$ (1) was shown to be useful in the processing of graphene ${ }^{18}$ as well as in $\mathrm{MOF}^{19}$ synthesis, membrane synthesis ${ }^{20}$ and resin swelling applications. ${ }^{21}$ Traditional organic reactions, such as $\mathrm{S}_{\mathrm{N}} 2, \mathrm{~S}_{\mathrm{N}} \mathrm{Ar}^{14}$ and acyl substitution processes ${ }^{22}$ have also been accomplished in Cyrene $^{\mathrm{TM}}$ (1). In addition, palladium-catalyzed cross coupling reactions, such as the Sonogashira, Cacchi type annulations ${ }^{23}$ and Suzuki-Miyaura reactions ${ }^{24}$ were conducted using Cyrene ${ }^{\mathrm{TM}}$ (1) as a solvent. Interestingly, a number of processes were not compatible with Cyrene ${ }^{\mathrm{TM}}(\mathbf{1})$ as a solvent, including bio-catalysis applications ${ }^{25}$ and situations where it could act as an electrophile. ${ }^{26}$ During the course of our study, Watson and co-workers reported the use of Cyrene ${ }^{\mathrm{TM}}$ (1) as a solvent in the HATU mediated synthesis of amides from carboxylic acid and amines in the presence of excess base (Scheme 1, eq. 2). ${ }^{27}$ Herein, we report the use of the bio-available solvent Cyrene ${ }^{\mathrm{TM}}$ (1) for the synthesis of amides from the reaction of amines and acid chlorides (Scheme 1, eq. 3). Molar efficiency calculations, conducted on a semi-automated Excel based calculator, were used to guide the development of a workup, isolation and purification protocol that minimized the amount of waste that was produced. In addition, a study into the hydration of Cyrene $^{\mathrm{TM}}$ (1) showed the facile nature of its conversions to a geminal diol as well as the exothermic nature of this process. 


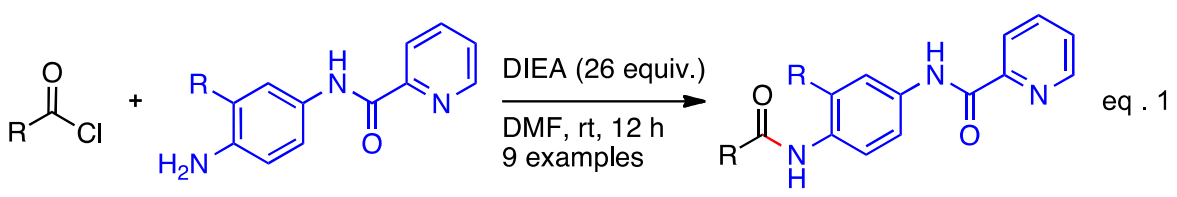

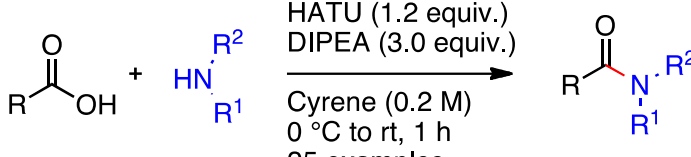

$$
\begin{aligned}
& 25 \text { examples } \\
& 63-100 \%
\end{aligned}
$$

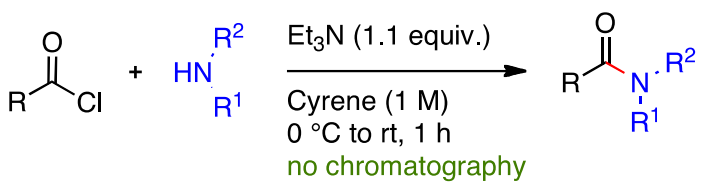

Scheme 1 Synthesis of amides in DMF and Cyrene ${ }^{\mathrm{TM}}(\mathbf{1})$

\section{EXPERIMENTAL SECTION}

General Procedure. To a stirred solution of an acid chloride ( $0.5 \mathrm{mmol}, 1.0$ equiv.) in Cyrene ${ }^{\mathrm{TM}}(\mathbf{1}, 0.5$ $\mathrm{mL}, 1 \mathrm{M})$ at $0{ }^{\circ} \mathrm{C}$ were added triethylamine $(0.55 \mathrm{mmol}, 1.1$ equiv. $)$ and a primary amine $(0.5 \mathrm{mmol}, 1.0$ equiv.). The resultant mixture was allowed to warm to $\mathrm{rt}$ over $1 \mathrm{~h}$. Water $(5 \mathrm{~mL})$ was added and the mixture was stirred until the product precipitated. The precipitate was filtered and washed with water to give the pure amide. For the preparation of NMR samples, the solid was dissolved in ethyl acetate, dried over sodium sulphate, filtered and the solvent was removed under reduced pressure.

\section{RESULTS AND DISCUSSION}

To begin the study into the use of Cyrene ${ }^{\mathrm{TM}}(\mathbf{1})$ as a solvent for the synthesis of amides the reaction of 4-fluorobenzoyl chloride (2a) and a variety of amines $\mathbf{3}$ was investigated (Table 1). Thus, the reaction of the acid chloride $\mathbf{2 a}$ with pyrrolidine (3a), aniline $(\mathbf{3 b})$ and benzylamine (3c) in the presence of triethylamine afforded the desired amides 4-6 in good yields. Whilst the optimization of the reaction was straightforward, the isolation of the pure amides required further investigation. Three different work-up procedures were investigated and their molar efficiency values ${ }^{28,29}$ were calculated using a semi-automated Excel based calculator (vide infra). ${ }^{30}$ An aqueous work-up followed by column chromatography afforded (4-fluorophenyl)(pyrrolidine-1-yl)methanone $\mathbf{4 a}$ in excellent isolated yield (Table 1, entry 1). In contrast to our work on the synthesis of pyrrolidine-derived ureas, ${ }^{18}$ amide $4 \mathbf{a}$ did not precipitate upon the addition of ten equivalents of water. The crude reaction mixture was also loaded directly onto a silica gel column for purification, which gave the desired amide $\mathbf{4 a}$ in good yield. The removal of the aqueous work-up step resulted in a 1.4-fold increase in molar efficiency (Table 1, entry 1 vs. 2). Switching to the use of primary amines, aniline (3b) and benzylamine (3c), allow for the direct precipitation of the product amides $5 \mathbf{a}$ and $\mathbf{6 a}$, respectively, which did not require any additional isolation or purification. SAFETY NOTE: Addition of water to neat Cyrene $^{\mathrm{TM}}$ (1) is an exothermic process (vide infra). By removing the requirement for both an aqueous work-up and column chromatography, up to a 28 -fold increase in molar efficiency was achieved (Table 1, entry 1 vs. 4). Thus, one of the key challenges in the use of high boiling dipolar aprotic solvents, their separation from the product, was overcome by using this improved isolation procedure. Importantly, only bio-derived solvents, water and Cyrene ${ }^{\mathrm{TM}}(\mathbf{1})$, were required for the synthesis of amides from acid chlorides and primary amines.

Table 1 Optimization of the synthesis of amides 4-6 in Cyrene ${ }^{\mathrm{TM}}$ (1) using molar efficiency calculations.

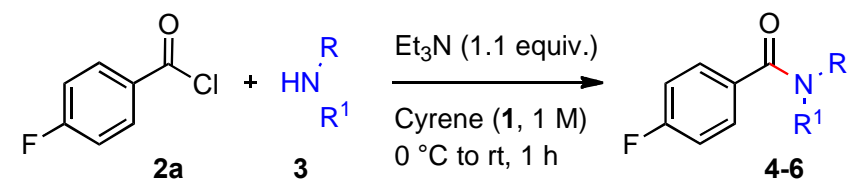




\begin{tabular}{|l|l|l|l|l|}
\hline Entry & Amine & Work-up & Yield (\%) & Relative Mol. E\% \\
\hline 1 & pyrrolidine & aqueous; then column & $91 \mathbf{4 a}$ & 1 \\
\hline 2 & pyrrolidine & column & $75 \mathbf{4 a}$ & 1.4 \\
\hline 3 & aniline & precipitate & $72 \mathbf{5 a}$ & 24 \\
\hline 4 & benzylamine & precipitate & $81 \mathbf{6 a}$ & 28 \\
\hline
\end{tabular}

With the optimized reaction and isolations procedure in hand, the reaction of aniline (3b) and benzylamine (3c) with acid chlorides 2 was investigated (Scheme 2). Fluoro- and brominated benzoyl chlorides gave the desired amides 5a-d / 6a-d in good yield. For example, the reaction of 2fluorobenzoyl chloride with either aniline or benzylamine, gave amides $\mathbf{5 c / 6}$ in greater than $70 \%$ isolated yield. Interestingly, in some cases an increased yield was obtained by stirring the aqueous mixture for $24 \mathrm{~h}$, but this was not always the case, c.f. amide 5a vs. 5c. Electron-rich acid chloride, 3,4dimethoxybenzoyl chloride afforded amides $\mathbf{5 e / 6 e}$ in high yield. The synthesis of amide $\mathbf{6 e}$ could be run on a $5.0 \mathrm{mmol}$ scale without a significant decrease in yield. It is possible that the electron rich nature of the system slows down the addition of water to the acid chloride leading to higher yields. Reactions between heterocyclic benzoyl chlorides, such as pyridine, thiophene, furan and benzothiophene with aniline (3b) gave amides $\mathbf{5 f - 5 i}$ in moderate yields. Slightly higher yields for acid chloride-containing heterocycles were observed when benzylamine (3c) was used as the nucleophile to form amides 6g-6i. Finally, aliphatic acid chlorides reacted with aniline (3b) or benzylamine (3c) to give amides $\mathbf{5 j}, \mathbf{k} / \mathbf{6 j}, \mathbf{k}$ in moderate yields. The reaction of acid chlorides that contained long alkyl chains did not give product amides that precipitated upon the addition of 10 equivalents of water. Based on in situ ${ }^{19} \mathrm{~F}$ NMR experiments (vide infra), amide formation is nearly quantitative, with the rest of the starting material being converted to the carboxylic acid. The majority of the water necessary for the hydrolysis of the acid chloride is introduced into the system via the use of reagent grade Cyrene $^{\mathrm{TM}}$ that has not been dried. The fluctuation in isolated yields is most likely a reflection of the solubility of the products in a 10:1 mixture of water to Cyrene ${ }^{\mathrm{TM}}(\mathbf{1})$. Alternative work-up procedures including sonication, varying the amount of water added and the addition of salts did not have a beneficial effect on the isolated yield of the products. 


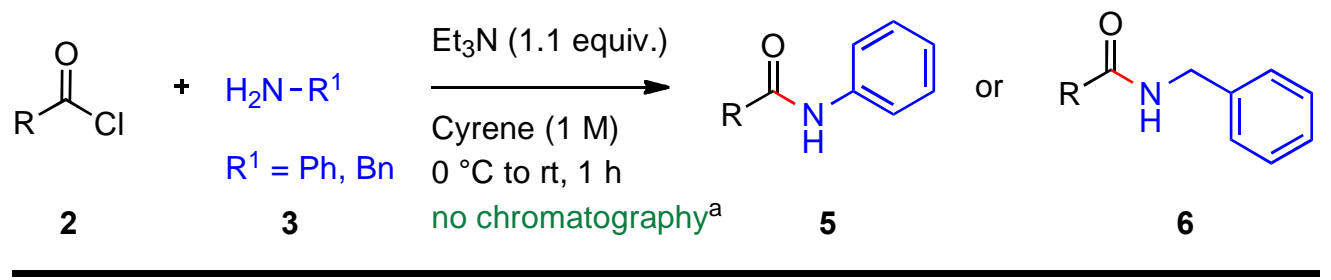<smiles>[R]NC(=O)c1ccc(F)cc1</smiles><smiles>[R]NC(=O)c1cccc(F)c1</smiles><smiles>[R7]NC(=O)c1ccccc1F</smiles><smiles>[R]NC(=O)c1ccc(Br)cc1</smiles><smiles>[R][R]([R])=P[Ba][Ba][Ba][Ba][Ba]</smiles><smiles>CCCNC(=O)c1ccc(OC)c(OC)c1</smiles><smiles>[R7]NC(=O)c1cccnc1</smiles><smiles>[R7]NC(=O)c1cccs1</smiles><smiles>[R7]NC(=O)c1ccco1</smiles>

$\mathrm{R}^{1}=\mathrm{Ph}, \mathbf{5 e} 83 \%$ $R^{1}=P h, 5 f 32 \% b$

$\mathrm{R}^{1}=\mathrm{Ph}, \mathbf{5 g} 55 \%$<smiles>NC(=O)c1sc2ccccc2c1Cl</smiles><smiles>NC(=O)C1CC1</smiles>

$\mathrm{R}^{1}=\mathrm{Ph}, \mathbf{5 i} 45 \%$

$\mathrm{R}^{1}=\mathrm{Ph}, \mathbf{5 j}$ 46\% (49\%)<smiles>NC(=O)C1CCC1</smiles>

$\mathrm{R}^{1}=\mathrm{Bn}, \mathbf{6} \mathbf{i} 47 \%(74 \%)^{\mathrm{b}}$ $\mathrm{R}^{1}=\mathrm{Bn}, \mathbf{6 j} 64 \%$

a aqueous work-up ${ }^{b} 24 \mathrm{~h}$ stir in water ${ }^{c} 5.0 \mathrm{mmol}$ scale

Scheme 2 Synthesis of amides from acid chlorides and primary amines in Cyrene (1)

Next, the addition of a secondary amide to a variety of acid chlorides was investigated. Pyrrolidine (3a) was reacted with electron-deficient, electron-rich, heterocyclic and alkyl acid chlorides under the standard conditions used for the primary amines (Scheme 3). As stated previously, the resultant amides did not precipitate from the solution upon the addition of water, but rather oiled out to form a nonseparable emulsion. In order to increase molar efficiency, a direct chromatography method was employed to isolate and purify the amides. This is despite the fact that a traditional work-up / purification protocol resulted in an increased isolated yield of the tertiary amide. For comparison, an aqueous work-up followed by column chromatography for amide $\mathbf{4 a}$ gave a $91 \%$ yield, whilst direct chromatography (i.e. loading the crude reaction directly onto the silica gel) of the solution afforded amide $\mathbf{4 a}$ in $75 \%$ yield. Electron rich and heterocyclic acid chlorides afforded the desired amides $\mathbf{4 e}$ and $\mathbf{4 h}$, respectively, in slightly higher yields than their halogenated counterparts, $\mathbf{4 a}, \mathbf{4 b}$ and $\mathbf{4 d}$. Finally, the reaction of pyrrolidine (3a) with cyclopropanecarbonyl chloride afforded the desired amide $\mathbf{4 j}$ in moderate yield. Based on the substrate scope study it was found that amides derived from primary aliphatic or benzylic amines can be precipitated directly from Cyrene ${ }^{\mathrm{TM}}$ (1) whereas the products from the reaction of secondary amines required purification by column chromatography. 


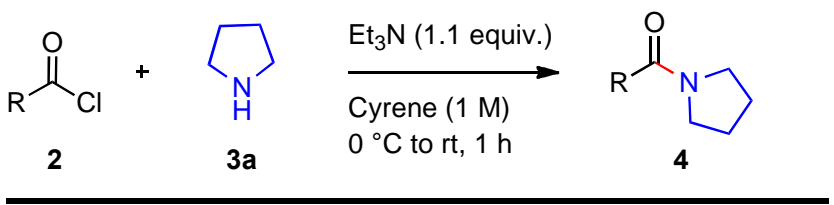<smiles>O=C(c1ccc(F)cc1)N1CCCC1</smiles><smiles>O=C(c1ccc(Br)cc1)N1CCCC1</smiles>

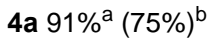
4b $76 \%$

4d $50 \%$ b<smiles>COc1ccc(C(=O)N2CCCC2)cc1OC</smiles><smiles>O=C(C1CC1)N1CCCC1</smiles>

$4 e 69 \%$

4h $68 \%{ }^{b}$

4j $50 \%$ b

${ }^{a}$ aqueous work-up ${ }^{b}$ solution directly purified by column chromatography

Scheme 3 Synthesis of amides 4 from acid chlorides and primary amines in Cyrene ${ }^{\mathrm{TM}}(\mathbf{1})$

The rate of the formation of amides from acid chlorides and amines in Cyrene ${ }^{\mathrm{TM}}$ (1) versus the industrial standard solvents DMF, NMP and acetonitrile were examined using in situ ${ }^{19} \mathrm{~F}$ NMR with hexafluorobenzene as an internal standard. Monitoring the reaction of 3-fluorobenzoyl chloride and aniline $(\mathbf{3 b})$ in the presence of triethylamine at room temperature showed complete conversion to amide $\mathbf{5 b}$ in less than 5 minutes for the four solvents that were investigated.

\section{INVESTIGATION INTO THE HYDRATION OF CYRENE ${ }^{\text {TM }}$ (1)}

A study into the hydration of Cyrene ${ }^{\mathrm{TM}}$ (1) was undertaken in order to better understand why it could be separated from the product amide via the addition of water. Whilst the hydrate of Cyrene $7^{31}$ as well as related 6,8-dioxabicyclo[3.2.1]octanone ring systems in which there is a substituent at the $\beta$-position are reported, ${ }^{32,33}$ at the start of our study there is was no NMR data available for the hydrate or information on the effect of water concentration on the equilibrium. Very recently, De bryun $e t$ al. reported on the hydration of Cyrene ${ }^{\mathrm{TM}}(\mathbf{1})$ and the ability of the solutions to solvate simple organic compounds. ${ }^{34}$ In contrast to this work, mixtures of varying concentrations of $\mathrm{D}_{2} \mathrm{O}$ and Cyrene ${ }^{\mathrm{TM}}$ (1) were subjected to NMR analysis to provide insights into the equilibrium process. SAFETY NOTE: Addition of water to neat Cyrene ${ }^{\mathrm{TM}}(\mathbf{1})$ is an exothermic process. It was found that the addition of 2.5 $\mathrm{mL}$ of water to $2.5 \mathrm{~mL}$ of Cyrene ${ }^{\mathrm{TM}}(\mathbf{1})$ resulted in an increase in temperature of over $14{ }^{\circ} \mathrm{C}$ ( $c f$. Figure S12). ${ }^{26}$ Initially, it was found that in the presence of 10 equivalents of $\mathrm{D}_{2} \mathrm{O}, 96 \%$ of Cyrene ${ }^{\mathrm{TM}}(\mathbf{1})$ was hydrated to geminal diol 7. No ring opening of the cyclic acetal of Cyrene ${ }^{\mathrm{TM}}(\mathbf{1})$ was observed in this study. Importantly, the structure of geminal diol 7 was confirmed by 2D NMR experiments with nOe observed in the HMBC spectra between the proton adjacent to the cyclic acetal (circled in red) and the carbons next to the ethers as well as alpha to the geminal diol, highlighted in green, yellow and blue, respectively. Furthermore, as the percent of $\mathrm{D}_{2} \mathrm{O}$ increased from $1 \%$ to $99 \%$ the equilibrium shifted from ketone 1 to geminal diol 7. At a ratio of 1:1 of $\mathrm{D}_{2} \mathrm{O}$ to Cyrene ${ }^{\mathrm{TM}}(\mathbf{1})$, over $80 \%$ of the ketone was hydrated. These results are in stark contrast to a simple ketone, such as acetone, which exists predominately as the carbonyl in aqueous solution. ${ }^{35}$ The facile hydration of Cyrene ${ }^{\mathrm{TM}}$ (1) and the subsequent change in its solvating ability helps to explain why amides $\mathbf{5}$ and $\mathbf{6}$ precipitated upon the addition of water.. Interestingly, when $1 \mathrm{M}$ solutions of a 1:1 mixture of Cyrene ${ }^{\mathrm{TM}}$ (1) to $\mathrm{D}_{2} \mathrm{O}$ in DMSO- $\mathrm{d}^{6}, \mathrm{MeCN}-\mathrm{d}^{3}$ or acetone- $\mathrm{d}^{6}$ over the same concentration range were analyzed by ${ }^{1} \mathrm{H}$ NMR, only the non-hydrated keto form of Cyrene ${ }^{\mathrm{TM}}(\mathbf{1})$ was observed. These results suggest that in the presence of an excess of organic solvent that the keto form is highly favored and that Cyrene ${ }^{\mathrm{TM}}(\mathbf{1})$ will behave like a dipolar aprotic solvent. Control over the hydration of Cyrene ${ }^{\mathrm{TM}}$ (1) should allow for its facile recycling and lead to novel applications. 

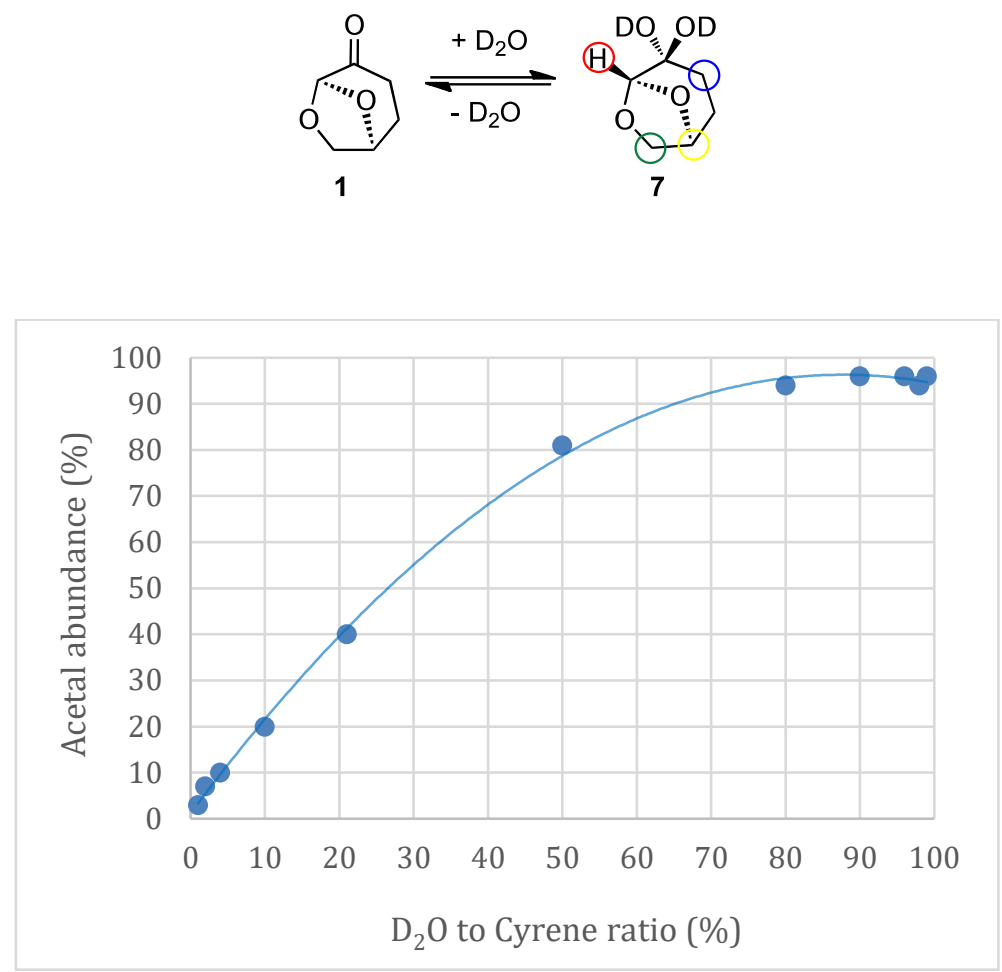

Figure 2 Hydration of Cyrene ${ }^{\mathrm{TM}}$ (1) to form geminal diol $\mathbf{7}$ as the amount of $\mathrm{D}_{2} \mathrm{O}$ is changed. Solid lines between points are visual aids.

\section{MOLAR EFFICIENCY CALCULATOR AND CALCULATIONS}

In order to compare the efficiency of our method to existing protocols, molar efficiency calculations were undertaken using the method of Watson and co-workers ${ }^{24,25}$ in which:

Molar efficiency $($ Mol. E\% $)=\left[\frac{\text { moles product }}{\text { moles starting material }+ \text { additives }+ \text { catalysts }+ \text { solvents }}\right] \times 100$

Molar efficiency calculations are a useful way to calculate reaction efficiency in discovery medicinal chemistry as they enable comparisons of the multitude of transformations that are used at this phase of research. Also, this green metric allow for the cross-comparison of the subtleties within a particular reaction and it is this ability to rapidly quantify difference that has been used in this research. In order to quickly access the molar efficiency of the reported method and compare it to existing literature a semi-automated Excel based Mol. E\% calculator was developed. ${ }^{26}$ The calculator automates many of the efficiency calculation and converts solvents from $\mathrm{mL}$ to $\mathrm{mmol}$. In order to evaluate all of the relevant papers a number of assumptions needed to be made about standard work-up procedures for which no detailed information is generally provided. The following standards were used:

1. Chromatography: $100 \mathrm{~g} \mathrm{SiO}_{2}$ per $1.0 \mathrm{mmol}$ (up to $10 \mathrm{mmol}$ ): $50 \mathrm{~g} \mathrm{SiO}_{2}$ per $1.0 \mathrm{mmol}$ (up to 10 $\mathrm{mmol}$ ) using an automated purification system

2. Chromatography: $1.0 \mathrm{~L}$ solvent for first $1.0 \mathrm{mmol}$ and then $500 \mathrm{~mL}$ solvent for each mmol thereafter (up to $10 \mathrm{mmol}$ ): $0.5 \mathrm{~L}$ solvent and then $250 \mathrm{~mL}$ solvent for each mmol thereafter (up to $10 \mathrm{mmol}$ ) when using an automated purification system

3. Silica gel plug: $10.0 \mathrm{~g}$ silica gel (up to $10 \mathrm{mmol}$ )

4. Recrystallization: $5.0 \mathrm{~mL}$ per $1.0 \mathrm{mmol}$ (up to $10 \mathrm{mmol}$ )

5. Drying agent: $\left(\mathrm{MgSO}_{4}\right.$ or $\left.\mathrm{Na}_{2} \mathrm{SO}_{4}\right) 2.0 \mathrm{~g}$ per $1 \mathrm{mmol}$ (up to $10 \mathrm{mmol}$ ) 
With the calculator in hand, the Mol. E\% of the optimized protocol for the synthesis of amides was compared with standard reaction methods in the problematic solvents $\mathrm{DMF}$ and $\mathrm{CH}_{2} \mathrm{Cl}_{2}$ as well as the commonly used solvent THF (Table 2 and ESI). As stated previously, it was found that changing from an aqueous work-up / chromatography to a precipitate protocol in our study resulted in up to a 28 -fold increase in Mol. E\% (Table 2, entries 1-4). Similar amidation reactions in DMF were found to be significantly less efficient, with the precipitate protocol showing up to a 55-fold improvement (Table 2, entries 2,3 vs. 5,6). Methods that used the halogenated solvent $\mathrm{CH}_{2} \mathrm{Cl}_{2}$ were found to be approximately 14-fold less efficient (Table 2, entries 2,3 vs. 7,8). Finally, a similar amidation method employing THF as the solvent was found to be one of the least efficient protocols of those investigated (Table 2, entry 9). Thus, the newly developed Excel based calculator allowed for the rapid calculation of the Mol. E\% values for various solvent systems and demonstrated that the precipitation method is up to 55-fold better than standard industrial processes. In addition, the process mass intensity (PMI) ${ }^{36}$ of each of the nine protocols was calculated. Satisfyingly, the same trend was observed with the precipitation methods showing a significant improvement on existing protocols (Tabel 2, entries 3 and 4 vs. 5-9).

Table 2 Comparison of Mol. E\% of amide forming reactions

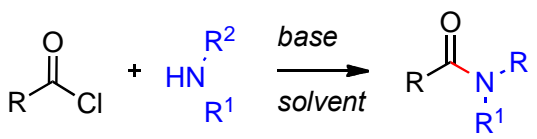

\begin{tabular}{|l|l|l|l|l|l|l|l|}
\hline Entry & Acid Chloride 1 & Amine 2 & Solvent & Work-up $^{\boldsymbol{a}}$ & Mol. E\% & $\begin{array}{l}\text { Relative } \\
\text { Mol. E\% }\end{array}$ & PMI \\
\hline 1 & 4-Fluorobenzyl chloride & Pyrrolidine & Cyrene & A & 0.0053 & 2.0 & 6119 \\
\hline 2 & 4-Fluorobenzyl chloride & Pyrrolidine & Cyrene & B & 0.0070 & 2.7 & 6109 \\
\hline 3 & 4-Fluorobenzyl chloride & Aniline & Cyrene & C & 0.123 & 47 & 75 \\
\hline 4 & 4-Fluorobenzyl chloride & Benzylamine & Cyrene & C & 0.143 & 55 & 63 \\
\hline $5^{37}$ & Chloroformate & 2-Phenylethylamine & DMF & A & 0.0111 & 4.3 & 3582 \\
\hline $6^{38}$ & $\begin{array}{l}\text { 4-Fluoro-3- } \\
\text { (trifluoromethyl)benzoyl } \\
\text { chloride }\end{array}$ & $\begin{array}{l}\text { 1-Benzyl-2,3- } \\
\text { dihydro-1H- } \\
\text { pyrrolo[2,3- } \\
\text { b]quinolin-4- } \\
\text { ylamine }\end{array}$ & DMF & A & 0.0026 & 1 & 7807 \\
\hline $7^{39}$ & 4-Fluorobenzyl chloride & $\begin{array}{l}\text { N-(2-Aminophenyl)- } \\
\text { acetamide }\end{array}$ & $\mathrm{CH}_{2} \mathrm{Cl}_{2}$ & $\mathrm{~A}$ & 0.0073 & 2.8 & 10630 \\
\hline $8^{40}$ & 4-Fluorobenzyl chloride & 2-Bromoaniline & $\mathrm{CH}_{2} \mathrm{Cl}_{2}$ & $\mathrm{~A}$ & 0.0115 & 4.4 & 3154 \\
\hline $9^{41}$ & 3-Fluorobenzyl chloride & $\begin{array}{l}5,7- \\
\text { Dichloroquinolin-8- } \\
\text { amine }\end{array}$ & $\mathrm{THF}^{2}$ & $\mathrm{~A} \& \mathrm{D}$ & 0.0026 & 1 & 1777 \\
\hline
\end{tabular}

${ }^{a}$ Work-up conditions: (A) aqueous work-up followed by column chromatography (B) column chromatography (C) precipitation (D) recrystallization

\section{CONCLUSION}

In conclusion, a molar efficient protocol for the synthesis of amides from acid chlorides and amines has been developed. The substrate scope of this green and mild method has been investigated with respect to acid chlorides and primary amines. This method provides an important alternative approach to the current industrial use of halogenated solvents and dimethylformamide. Importantly, the work-up procedure eliminates the need for the use of any non-bioderived organic solvents from the process. The simple addition of water allows for complete removal of the Cyrene ${ }^{\mathrm{TM}}(\mathbf{1})$ without the need for extensive isolation and purification protocols, which are required using existing technologies. In order to rapidly compare this method with those previously reported an Excel based Mol. E\% calculator was developed. Mol. E\% calculations showed that the Cyrene ${ }^{\mathrm{TM}}$ (1) precipitation method is significantly more efficient than the previously reported protocols using more toxic solvents, such as DMF and dichloromethane. This protocol allows for the rapid synthesis of amides under mild, more sustainable conditions.

\section{ASSOCIATED CONTENT}

Experimental procedures, ${ }^{1} \mathrm{H} /{ }^{13} \mathrm{C}\left\{{ }^{1} \mathrm{H}\right\} /{ }^{19} \mathrm{~F}$ NMR data for all compounds, molar efficiency calculations and Excel based Mol. E\% calculator. This material is available free of charge via the Internet at http://pubs.acs.org. 


\section{AUTHOR INFORMATION}

\section{Corresponding Author}

*E-mail: j.e.camp@hud.ac.uk

\section{Notes}

The authors declare no competing financial interest.

\section{ACKNOWLEDGEMENTS}

This work was supported by the School of Applied Sciences at the University of Huddersfield (studentship T.W.B). We gratefully acknowledge the donation of $\mathrm{Cyrene}^{\mathrm{TM}}$ as well as the helpful discussions with Tony Duncan, Dr Warwick Raverty and Jeff Eaves from Circa Group, Melbourne, Australia. We also acknowledge helpful discussions with Prof. Andy Laws, University of Huddersfield, who assisted with the structural determination of geminal diol 7.

\section{REFERENCES}

${ }^{1}$ (a) A. Henninot, J. C. Collins and J. M. Nuss, J. Med. Chem., 2018, 61, 1382-1414; (b) D. J. Newman, Expert Opin. Drug Dis., 2018, 13, 379-385; (c) D. G. Brown and J. Boström, J. Med. Chem., 2016, 59, 4443-4458; (d) T. W. J. Cooper, I. B. Campbell and S. J. F. Macdonald, Angew. Chem. Int. Ed., 2010, 49, 8082-8091; (e) J. S. Carey, D. Laffan, C. Thomson and M. T. Williams, Org. Biomol. Chem., 2006, 4, 2337-2347.

2 https://www.genengnews.com/the-lists/the-top-15-best-selling-drugs-of-2017/77901068 (accessed July 16th 2018)

3 https://www.fool.com/investing/2017/03/13/the-19-best-selling-prescription-drugs-of-all-time.aspx (accessed July 16th 2018)

${ }^{4}$ For recent examples, see: (a) B. J. Landi, H. J. Ruf, J. J. Worman and R. P. Raffarlle, J. Phys. Chem. B, 2004, 108, 17089-17095; (b) W.-B. Wang and E. J. Roskamp, E. J. J. Org. Chem., 1992, 57, 61016103; (c) S. O. Kang, R. A. Begum and K. Bowman-James, Angew. Chem. Int. Ed., 2006, 45, 78827894; (d) Q. Li, S. Wang, S. Zhou, G. Yang, X. Zhu and Y. Liu, J. Org. Chem., 2007, 72, 6763-6767; (e) M. Tsakos and C. G. Kokotos, Tetrahedron, 2013, 69, 10199-10222; (f) G. Koutoutlogenis, N. Kaplaneris and C. G. Kokotos, Beilstein J. Org. Chem., 2016, 12, 462-495; (g) I. Vlasserou, M. Sfetsa, D.-T. Gerokonstantis, C. G. Kokotos and P. Mountevelis-Minakakis, Tetrahedron, 2018, 74, 23382349.

5 (a) D. C. Braddock, P. D. Lickiss, B. C. Rowley, D. Pugh, T. Purnomo, G. Santhakumar and S. J. Fussell, Org. Lett., 2018, 20, 950-953; (b) J. Das and D. Banerjee, J. Org. Chem., 2018, 83, 33783384; (c) M. T. Sabatini, L. T. Boulton and T. D. Sheppard, Sci. Adv. 2017, 3:e1701028; (d) A. O. Gálvez, C. P. Schaack, H. Noda and J. W. Bode, J. W. J. Am Chem. Soc., 2017, 139, 1826-1829; (e) M. Sayes and A. B. Charette, Green Chem., 2017, 19, 5060-5064; (f) D. D. S. Sharley and J. M. J. Williams, Chem. Comm., 2017, 53, 2020-2023; (g) G. N. Papadopoulos and C. G. Kototos, J. Org. Chem., 2016, 81, 7023-7028.

${ }^{6}$ D. W. Engers, J. R. Field, U. Le, Y. Zhou, J. D. Bolinger, R. Zamorano, A. L. Blobaum, C. K. Jones, S. Jadhav, C. D. Weaver, P. J. Conn, C. W. Lindsley, C. M. Niswender and C. R. Hopkins, J. Med. Chem., 2011, 54, 1106-1110.

${ }^{7}$ Scifinder searches of the reaction of aryl chlorides with anilines or benzylamines to afford amides revealed that of 37,617 reactions, 25,527 were run in halogenated solvents or diploar aprotics (DMF,NMP), which is $68 \%$ of all reported reactions in the database. Search conducted on July $16^{\text {th }}$ 2018.

${ }^{8}$ P. T. Anastas and J. C. Warner, Green Chemistry: Theory and Practice, Oxford University Press: New York, 1998.

${ }^{9}$ D. J. C Constable, P. J. Dunn, J. D. Hayler, G. R. Humphrey, J. L. Leazer Jr, R. J. Linderman, K. Lorenz, J. Manley, B. A. Pearlman, A. Wells, A. Zaks and T. Y. Zhang, Green Chem., 2007, 9, 411420.

${ }^{10}$ For selected examples of solvent selection guides, see: (a) C. Capello, U. Fischer and K Hungerbühler, Green Chem. 2007, 9, 927-934; (b) P. G. Jessop, Green Chem., 2011, 13, 1391-1398; (c) R. K. Henderson, D. J. C. Constable, S. R. Alston, G. G. A. Inglis, G. Fisher, J. Sherwood, S. P. 
Binks, and A. D. Curzons, Green Chem., 2011, 13, 854-862; (d) D. Prat, A. Wells, J. Hayler, H. Sneddon, C. R. McElroy, S. Abou-Sheshada and P. J. Dunn, Green Chem., 2016, 18, 288-296.

11 Another possible green alternative dipolar aprotic solvents is dimethyl isosorbide, see: (a) S. Lawreson, M. North, F. Peigneguy and A. Routledge, Green. Chem., 2017, 19, 952-962; (b) Y. E. Jad, T. Govender, H. G. Kruger, A. El-Faham and B. G. de la Torre, Org. Process Res. Dev., 2017, 21, 365-369.

${ }^{12}$ http://www.chemsafetypro.com/Topics/EU/REACH_annex_xvii_REACH_restricted_substance_list.h tml

${ }^{13}$ For recent publications on the use of more sustainable solvents and solvent selection guides, see: (a) C. M. Alder, J. D. Hayler, R. K. Henderson, A. M. Redman, L. Shukla, L. E. Shuster and H. F. Sneddon, Green Chem., 2016, 18, 3879-3890; (b) P. M. Murray, F. Bellany, L. Benhamou, D.-K. Bučar, A. B. Tabor and T. D. Sheppard, Org. Biomol. Chem., 2016, 14, 2373-2384; (c) C. R. McElroy, A. Constantinou, L. C. Jones, L. Summerton and J. H. Clark, Green Chem., 2015, 17, 3111-3121; (d) F. Pena-Pereira, A. Kloskowski and J. Namieśnik, Green Chem. 2015, 17, 3687-3705; (e) D. Prat, J. Hayler and A. Wells, Green Chem., 2014, 16, 4546-4551. (f) D. S. MacMillan, J. Murray, H. F. Sneddon, C. Jamieson, and A. J. B. Watson, Green Chem., 2013, 15, 596-600.

${ }^{14}$ For recent examples of the use of aqueous or alcoholic solutions in place of high risk solvents from our laboratory, see: (a) R. P. Lester, T. Bham, T. W. Bousfield, W. Lewis and J. E. Camp, J. Org. Chem., 2016, 81, 12472-12477; (b) S. Kyne and J. E. Camp, ACS Sustainable Chem. Eng., 2017, 5, 41-48; (c) J. E. Camp, J. J. Dunsford, O. S. G. Dacosta, R. K. Blundell, J. Adams, J. Britton, R.J. Smith, T. W. Bousfield and M. W. Fay, RSC Adv., 2016, 6, 16115-16131. (d) M. Rezayat, R. K. Blundell, J. E. Camp, D. A. Walsh and W. Thielemans, ACS Sustainable Chem. Eng., 2014, 2, 12411250. (e) J. E. Camp, J. J. Dunsford, E. P. Cannons, W. J. Restorick, A. Gadzhieva, M. W. Fay and R. J. Smith, ACS Sustainable Chem. Eng., 2014, 2, 500-505. (f) R. P. Lester and J. E. Camp, ACS Sustainable Chem. Eng., 2013, 1, 545-548.

${ }^{15}$ For other potential green replacements for traditional aprotic dipolar solvents, see: (a) H. L. Parker, J. Sherwood, A. J. Hunt and J. H. Clark, ACS Sustainable Chem. Eng., 2014, 2, 1739-1742; (b) D. Rasina, A. Kahler-Quesada, S. Ziarelli, S. Waratz, H. Cao, S. Santoro, L. Ackermann and L. Vaccaro, Green Chem., 2016, 18, 5025-5030; (c) K. L. Wilson, J. Murray, H. F. Sneddon, C. Jamieson, A. J. B. Watson, Synlett, 2018, 29, 2293-2297.

${ }^{16}$ For a review, see: J. E Camp, ChemSusChem, 2018, 11, 3048-3055.

${ }^{17}$ J. Sherwood, M. De bruyn, A. Constantinou, L. Moity, C. R. McElroy, T. J. Farmer, T. Duncan, W. Raverty, A. J. Hunt and J. H. Clark, Chem. Comm., 2014, 50, 9650-9652.

18 (a) H. J. Salavagione, J. Sherwood, M. De bruyn, V. L. Budarin, G. J. Ellis, J. H. Clark and P. S. Shuttleworth, Green Chem., 2017, 19, 2550-2560; (b) D. H. Gharib, S. Gietman, F. Malherbe and S. E. Moulton, Carbon, 2017, 123, 695-707.

${ }^{19}$ J. Zhang, G. B. White, M. D. Ryan, A. J. Hunt and M. J. Katz, ACS Sustainable Chem. Eng. 2016, 4, 7186-7192.

${ }^{20}$ T. Marino, F. Galiano, A. Molino and A. Figoli. J. Membrane Sci. 2019, 580, 224-234.

${ }^{21}$ (a) S. Lawrenson, M. North, F. Peigneguy and A. Routledge, Green Chem., 2017, 19, 952-962; (b) Y. Ran, F. Byrne, I. Ingram and M. North. Chem. Euro. J., DOI:10.1002/chem.201900228.

${ }^{22}$ L. Mistry, K. Mapesa, T. W. Bousfield and J. E. Camp, Green Chem., 2017, 19, 2123-2128.

${ }^{23}$ K. L. Wilson, A. R. Kennedy, J. Murray, B. Greatrex, C. Jamieson and A. J. B. Watson, Beilstein J. Org. Chem., 2016, 12, 2005-2011.

${ }^{24}$ K. L. Wilson, J. Murray, C. Jamieson and A. J. B. Watson, Cross-Coupling. Synlett, 2018, 29, 650654.

25 (a) A. G. Lanctôt, T. M. Attard, J. Sherwood, C. R. McElroy and A. J. Hunt, RSC Adv., 2016, 6, 48753-48756; (b) A. lemhoff, J. Sherwood, C. R. McElroy and A. J. Hunt, Green Chem., 2018, 20, $136-140$.

${ }^{26}$ H. A. L. Phuong, L. Cseri, G. F. S. Whitehead, A. Garforth, P. Budd and G. Szekely, RSC Adv., 2017, 7, 53278-53289.

${ }^{27}$ K. L. Wilson, J. Murray, C. Jamieson, A. J. B. Watson, Org. Biomol. Chem., 2018, 16, 2851-2854.

${ }^{28}$ F. I. McGonagle, H. F. Sneddon, C. Jamieson and A. J. B. Watson, ACS Sustainable Chem. Eng., 2014, 2, 523-532.

${ }^{29}$ For recent examples of Mol. E\% calculations, see: (a) D. Malferrari, N. Armenise, S. Decesari, P. Galletti and E. Tagiavini, ACS Sustainable Chem. Eng., 2015, 3, 1579-1588; (b). N. R. Agrawal, S. P. Bahekar, P. B. Sarode, S. S. Zade and H. S. Chandak, RSC Adv., 2015, 5, 47053-47059; (c) B. T. Reid and S. M. Reed, Green Chem., 2016, 18, 4263-4269; (d) Manish, M. K.; Madhunkar, G. D.; Jayant, M. G. Solvent-Free Synthesis of Thiobarbituric Acids Using Amberlyst-15 as a Green Catalyst. Current 
Green Chem. 2017, 4, 50-56; (e) J. E. Camp, T. W. Bousfield, J. J. Dunsford, J. Adams, J. Britton, M. W. Fay, A. Angelis-Dimakis. Synthesis 2018, 50, 3862-3874.

${ }^{30}$ See the ESI for full details.

${ }^{31}$ F. Shafizadeh and P. P. S. Chin, P. P. S. Carbohydr. Res., 1977, 58, 79-87.

${ }^{32}$ S. H. Krishna, T. W. Walker, J. A. Dumesic and G. W. Huber, ChemSusChem, 2017, 10, 129-138.

${ }_{33}$ A. V. Samet, M. E. Niyazymbetov and V. V. Semenov, J. Org. Chem., 1996, 61, 8786-8791.

${ }^{34}$ M. De bruyn, V. L. Budarin, A. Misefari, S. Shimizu, H. Fish, M. Cockett, A. J. Hunt, H. Hofstetter, B. M. Weckhuysen, J. H. Clark and D. J. Macquarrie, ACS Sustainable Chem. Eng., 2019, 7, 78787883.

35 (a) Y. Chiang, A. J. Kresge, Y. S. Tang and J. Wirz, J. Am. Chem. Soc., 1984, 106, 460-463; (b) T. Shikata and M. Okuzono, J. Phys. Chem. B., 2013, 117, 7718-7723.

${ }^{36}$ C. Jiménez-González, C. S. Ponder, Q. Broxterman, and J. Manley, Org. Process Res. Dev., 2011, 15. 912-917

${ }^{37}$ H. Kurouchi, K. Kawamoto, H. Sugimoto, S. Nakamura, Y. Otani and T. Ohwada, J. Org. Chem., 2012, 77, 9313-9328.

${ }^{38}$ B. D. Lee, Z. Li, K. J. French, Y. Zhuang, Z. Xia and C. D. Smith, J. Med. Chem., 2004, 47, 14131422.

${ }^{39}$ M. D. Reddy, A. N. Blanton and E. B. Watkins, J. Org. Chem., 2017, 82, 5080-5095.

${ }^{40}$ W. Li and X.-F. Wu, J. Org. Chem., 2014, 79, 10410-10416.

${ }^{41}$ M. Konishi, K. Tsuchida, K. Sano, T. Kochi and F. Kakiuchi, J. Org. Chem., 2017, 82, 8716-8724 